\title{
The anti-caries activity and toxicity of an experimental propolis-containing varnish
}

\begin{abstract}
Mariana Passos DE LUCA(a) Irlan Almeida FREIRES(b)

Alfonso GALA-GARCÍA(c)

Vagner Rodrigues SANTOS(d)

Miriam Pimenta VALE(a)

Severino Matias de ALENCAR ${ }^{(e)}$

Pedro Luiz ROSALEN(f)
\end{abstract}

(a) Universidade Federal de Minas Gerais UFMG, School of Dentistry, Department of Pediatric Dentistry and Orthodontics, Belo Horizonte, MG, Brazil.

(b) University of Florida, College of Dentistry, Department of Oral Biology, Gainesville, FL, United States.

(c) Universidade Federal de Minas Gerais UFMG, School of Dentistry, Department of Restorative Dentistry, Belo Horizonte, MG, Brazil.

(d) Universidade Federal de Minas Gerais UFMG, School of Dentistry, Department of Oral Pathology and Oral Surgery, Belo Horizonte, MG, Brazil.

(e) Universidade de São Paulo - USP, "Luiz de Queiroz" College of Agriculture, Department of Agri-Food industry, Piracicaba, SP, Brazil.

(f) Universidade de Campinas - UNICAMP, Piracicaba Dental School, Department of Physiological Sciences, Piracicaba, SP, Brazil.

Declaration of Interests: The authors certify that they have no commercial or associative interest that represents a conflict of interest in connection with the manuscript.

\section{Corresponding Author:}

Mariana Passos De Luca

E-mail: delucamariana@gmail.com, rosalen@fop.unicamp.br

hitps://doi.org/10.1590/1807-3107BOR-2017.vol31.0045

Submitted: Aug 29, 2016

Accepted for publication: Mar 31, 2017

Last revision: Apr 20, 2017
Abstract: We investigated the anti-caries effects of an experimental propolis varnish in vivo, and further tested its toxicity against fibroblasts. Fifty-six SPF female Wistar rats were infected with Streptococcus mutans UA159 (SM) and allocated into four groups ( $\mathrm{n}=14$ /group): G1, propolis varnish (15\%/PV); G2, chitosan varnish (CV/vehicle); G3, gold standard (GS/Duraphat $\left.{ }^{\circledR}\right)$; and G4, untreated. The animals received a single varnish application on their molars and were submitted to a high cariogenic challenge (Diet-2000, 56\% sucrose, and $5 \%$ sucrose-added water, ad libitum) for 4 weeks. Total cultivable microbiota and SM were counted, and smooth-surface and sulcal caries were scored. PV, CV and GS cytotoxic effects were tested against fibroblasts. The data were analyzed using ANOVA with the TukeyKramer test $(p \leq 0.05)$. Total microbiota and SM counts did not differ among the treatments $(p=0.78)$, or in relation to the untreated group $(p=0.52)$. PV reduced development of smooth-surface enamel caries compared with the untreated group $(p=0.0018)$, with no significant difference from GS ( $p=0.92)$; however, the PV effects were no longer observed when the dentin was affected. Neither PV nor GS prevented enamel sulcal lesion onset, but GS significantly reduced the severity of dentinal sulcal lesions $(p<0.0001)$. No significant difference was observed in fibroblast viability between PV and GS $(p<0.0001)$. In conclusion, PV prevented smooth-surface enamel caries and showed low cell toxicity. Nevertheless, due to the high cariogenic challenge, its effects were not sustained throughout the experiment. Further studies are encouraged to establish a protocol to sustain the long-term anticaries activity of PV in the oral cavity.

Keywords: Propolis; Streptococcus mutans; Dental Caries; Models, Animal.

\section{Introduction}

Dental caries remains a major public health issue worldwide with high prevalence and significant social impact. ${ }^{1}$ It results from a demineralization process in which acidogenic and acidophilic bacteria embedded in a mature, well-arranged biofilm degrade the tooth substance, ultimately leading to cavitation. ${ }^{2}$

Although several studies have related the participation of other bacteria in the pathogenesis of dental caries, ${ }^{2,3,4,5}$ Streptococcus mutans plays a central role in the development of cariogenic biofilms, mainly due to its acid-tolerant and 
acidogenic characteristics. This microorganism uses dietary sucrose to synthetizeextracellular polysaccharides (EPS), which are functional structures that mediate its adherence to the tooth surfaces. The carbohydrate fermentation process creates low- $\mathrm{pH}$ microenvironments that favor enamel and dentin demineralization. ${ }^{6}$

Natural products are major sources of bioactive molecules and pharmaceutical leads, and have therefore contributed significantly to drug development. ${ }^{7}$ Among these, propolis is one such product that stands out for its biological properties, mainly as an antimicrobial, with direct application in dentistry. ${ }^{89}$ Its anti-caries mechanism of action is associated with inhibition of glucosyltransferases and downregulation of specific genes associated with stress survival and tolerance in S. mutans. ${ }^{10}$ Moreover, some flavonoids, terpenoids, isoflavones and other phenolic acids contained in propolis were found to diminish S. mutans acid production and tolerance. . $^{10,11,12}$

Overall, a large number of biological activities have been attributed to different types of propolis, including antimicrobial, antifungal, antitumor, and others. ${ }^{9}$ Propolis type 12, from southeastern Brazil ${ }_{1}^{13}$ demonstrated strong antibacterial effects and prevented caries development in rats. ${ }^{14}$ In addition, topical application of the ethanolic extract of other types of propolis was also found to effectively reduce the incidence and severity of carious lesions in vivo. ${ }^{14,15,16}$ However, the biological effects of propolis may vary according to the geographical origin and chemical composition of the collected sample. ${ }^{16}$

Varnishes are materials widely used in dentistry for the prevention of dental caries. ${ }^{17}$ Some active principles can be incorporated into these formulations to promote and prolong their anti-caries effects, including fluoride, with remineralizing action, ${ }^{18}$ and chlorhexidine, with antimicrobial action. ${ }^{19}$

An experimental propolis-containing varnish was developed by our research group, as reported elsewhere. ${ }^{20}$ Our previous findings demonstrated that the experimental varnish has in vitro antimicrobial activity against cariogenic bacteria, and showed a very satisfactory sustained release of propolis in vitro. ${ }^{20}$ These data have encouraged us to investigate the anti-caries activity of this experimental formulation, using an animal model under a high cariogenic challenge. Herein, we investigated the anti-caries effects of the experimental propolis varnish in a rat model, and further tested its toxicity against fibroblasts, to provide enough information to perform clinical trials and eventually promote future clinical use.

\section{Methodology}

\section{Animals}

Fifty-six specific pathogen-free (SPF) female Wistar rats were obtained from CEMIB (Multidisciplinary Center for Biological Research, University of Campinas, SP, Brazil) and maintained at the animal facility of Piracicaba Dental School (Piracicaba, SP, Brazil). All procedures were performed in accordance with the ethical standards for the use and care of the animals. This study had the prior approval of the Ethics Committee on Animal Use (CEUA, University of Campinas, SP, Brazil; protocol no. 3142-1).

\section{Experimental caries model}

The rats were initially screened for the presence of indigenous S. mutans on mitis salivarius agar (Difco Laboratories, Detroit, USA) and mitis salivarius agar plus bacitracin (MSB/Sigma Chemical Co., St Louis, USA.). This is a quality control of the SPF condition of the animals. The initial screening using MSA and MSB plates confirmed that all the animals were streptococci- and mutans streptococci-free. At the age of 21 days, the rats were infected with an actively growing overnight culture of $S$. mutans UA159 using a cotton swab, and then fed pellet chow, Diet2000 with $56 \%$ sucrose, ${ }^{21}$ plus $5 \%$ sucrose in drinking water ad libitum. ${ }^{22}$ At the age of 25 days, the animals were screened for the establishment of oral infection, by plating oral samples onto MSB agar plates. On the following day, the rats were randomly assigned to four groups ( $\mathrm{n}=14)$, anesthetized with chloral hydrate $(440 \mathrm{mg} / \mathrm{kg}$ ) and submitted to the following treatments: G1 - topical application of propolis varnish (PV) (type 12 propolis from southeastern Brazil $^{13}$ - propolis ethanolic extract, 15\%, w/v); G2 topical application of chitosan varnish $(\mathrm{CV})$ (varnish base, vehicle control); G3 - topical application of a gold-standard varnish (Duraphat ${ }^{\circledR}$, fluoride $2.26 \%$, w/v, positive control); and G4 - untreated group 
(negative control). The varnishes were applied on the occlusal surfaces of the molars using one microbrush per hemiarch. After topical application, the animals fasted for 2 hours and were kept in individual cages for four weeks. Diet2000, containing $56 \%$ of sucrose, and $5 \%$ sucrose-added sterile distilled water were provided ad libitum. The animals were weighed weekly, and their behavior and physical appearance were noted daily. At the end of the experiment, the animals were euthanized and submitted to microbiological analysis.

\section{Microbiological analysis}

The lower left jaw was aseptically dissected, suspended in $5.0 \mathrm{~mL}$ of sterile saline solution $(0.9 \%$ $\mathrm{NaCl}, \mathrm{w} / \mathrm{v})$, and sonicated using three 10-second pulses at 30W with 5-second intervals (Vibracell, Sonics \& Material Inc.), in order to obtain the maximum recoverable viable counts. A spiral plater (Whitley Automatic Spiral Plater, DW Scientific ${ }^{\circledR}$ ) was used to streak the suspensions onto blood agar (5\% sheep blood) and mitis salivarius agar containing $100 \mu \mathrm{g} / \mathrm{mL}$ streptomycin sulfate (MSB, Sigma $\left.{ }^{\circledR}\right)$, to determine the number of $\mathrm{CFU} / \mathrm{mL}$ of total cultivable microorganisms and S. mutans, respectively. ${ }^{23}$ The counting of total cultivable microbiota was performed (i) to determine the proportion (\%) of S. mutans in the oral cavity of the animals in relation to the other microorganisms, which is directly related to strain implantation on the tooth surfaces; (ii) to ensure that the animals from all the groups had a similar microbial load at the endpoint; (iii) to identify whether treatment significantly affects the indigenous total microbiota of the animals and could potentially cause a microbiological disturbance. Smoothsurface and sulcal caries and their severity (E, enamel lesion; Ds, slight dentinal caries; Dm, moderate dentinal caries $-3 / 4$ of the dentin affected; Dx, extensive dentinal caries - all dentin affected) were scored according to Larson's modification of Keyes' system. ${ }^{24}$ Determining of the caries score was blinded by codification of the jaws and performed by one calibrated examiner (Intraclass Correlation Coefficient: 0.93, which indicates excellent intra-rater agreement).

\section{Cytotoxic effects against 3T3-L1 fibroblasts}

Fibroblasts 3T3-L1 (ATCC ${ }^{\circledR}$ CL-173 ${ }^{\mathrm{TM}}$ ) were grown in DMEM-F12, supplemented by $10 \%$ synovial fibroblasts and $1 \%$ antibiotic-antimycotic solution (10,000 units of penicillin, $10 \mathrm{mg}$ of streptomycin and $25 \mu \mathrm{g} / \mathrm{mL}$ of Amphotericin B in $0.9 \%$ sodium chloride; Sigma, St. Louis, $\mathrm{MO}$ ) in humidified air $-5 \% \mathrm{CO}_{2}$ atmosphere at $37^{\circ} \mathrm{C}$. The materials tested were: a. culture medium + cells (control), b. culture medium, c. PV (type 12 propolis from southeastern Brazil - propolis ethanolic extract, 15\%, w/v), d. CV (varnish base, vehicle control), e. gold-standard (GS) varnish (Duraphat ${ }^{\circledR}$, fluoride $2.26 \%, \mathrm{w} / \mathrm{v}$, positive control), and $\mathrm{f}$. acetic acid $(1 \%, \mathrm{v} / \mathrm{v}) .{ }^{20}$

One millimeter of each product was placed on round glass coverslips (9-mm diameter) and dried under vacuum for $24 \mathrm{~h}$. Then the fibroblasts were plated into 48 -well microtiter plates $\left(4 \times 10^{5}\right.$ cells/well). After $4 \mathrm{~h}$, the cells received conditioned media respective to each experimental group. Cell conditioning was carried out for $1 \mathrm{~h}$, at $37^{\circ} \mathrm{C}$, in a humid atmosphere with $5 \% \mathrm{CO}_{2}$. Then the conditioned media of all the groups were replaced by fresh media. Cell mitochondrial activity was analyzed using the MTT-based method $24 \mathrm{~h}$ and $48 \mathrm{~h}$ after conditioning. ${ }^{25}$ Cell growth curves were plotted, and the absorbance data were transformed into percentages of viable cells.

\section{Statistical analysis}

Smooth-surface and sulcal caries scores were expressed as proportions of their maximum possible values (124 and 56, respectively). ${ }^{24}$ The data were submitted to one-way analysis of variance (ANOVA) followed by Tukey-Kramer HSD (Honest Standard Deviation) pairwise comparison test on JMP version 3.1 software, with a 5\% significance level.

\section{Results}

All the rats gained weight and remained apparently healthy and active throughout the experiment. The average weight gains among the individual groups of rats were not significantly different $(P>0.05$, data not shown).

As expected, no streptococci were detected in the animals prior to inoculation. The effects of the experimental PV and controls on the total oral microbiota and S. mutans (SM) counts of infected 
animals are expressed in Table 1. At the endpoint, the total microbiota and SM counts did not differ significantly among the treatments $(\mathrm{p}=0.78)$, or in relation to the untreated group $(\mathrm{p}=0.52)$, showing that microbial viability was not affected.

As seen in Table 2, PV reduced the development of smooth-surface enamel caries, as compared with the untreated group ( $p=0.0018)$, with no significant difference from the GS ( $p=0.92)$. Nevertheless,

Table 1. Effects of the treatment with experimental and control varnishes on total oral microbiota and Streptococcus mutans counts in rats submitted to a high cariogenic challenge for four weeks. The values are expressed as mean (standard deviation).

\begin{tabular}{|c|c|c|c|}
\hline Treatment & $\begin{array}{l}\text { Total microbiota } \\
\text { (CFU/mL) } \\
(\mathrm{M} \pm \mathrm{SD})\end{array}$ & $\begin{array}{l}\text { S. mutans } \\
\text { (CFU/mL) } \\
(M \pm S D)\end{array}$ & $\begin{array}{c}\% \text { S. mutans } \\
(M \pm S D)\end{array}$ \\
\hline Propolis varnish & $75.4(7.8)^{a}$ & $37.6(4.2)^{a}$ & $40.7(11.3)^{a}$ \\
\hline Gold standard* & $43.5(6.0)^{a}$ & $24.4(3.7)^{a}$ & $46.2(15.5)^{a}$ \\
\hline Chitosan Varnish** & $74.3(8.1)^{\mathrm{a}}$ & $38.7(4.7)^{\mathrm{a}}$ & $47.1(7.8)^{a}$ \\
\hline Untreated control $^{\mid * *}$ & $48.4(10.1)^{a}$ & $33.1(8.0)^{a}$ & $40.4(11.3)^{\mathrm{a}}$ \\
\hline
\end{tabular}

${ }^{*}$ Duraphat ${ }^{\circledR} ;{ }^{* *}$ vehicle control; "** untreated group. Different superscript letters in the same column indicate significant differences among treatments (One-way ANOVA with Tukey-Kramer HSD, p $\leq 0.05$ ). the anti-caries effects of PV that were no longer observed as smooth-surface carious lesions became more severe, that is, when the dentin was affected. There was no significant difference between PV and the untreated group $(\mathrm{p}=0.34,0.99$ and 0.48 , respectively), either for slight, moderate or extensive dentinal caries.

Neither the experimental nor the standard varnishes were able to prevent the onset of sulcal lesions in the enamel (Table 3). However, the GS significantly reduced the severity of the sulcal lesions, affecting dentin, as compared with the untreated group ( $\mathrm{p}<0.0001)$.

No macroscopic tissue changes or abnormalities were observed in the oral cavity of the animals throughout the whole experiment.

Toxicity assays were carried out in vitro to provide preliminary evidence on whether PV would pose a risk against host cells. As seen in Figures 1 and 2, no significant difference was observed in fibroblast viability between PV and the GS after 24-h or 48-h exposure, respectively $(\mathrm{p}<0.0001)$.

Table 2. Effects of the treatment with the experimental propolis varnish on the development and severity of smooth-surface caries in rats. The values of the of the caries scores are given as mean \pm standard deviation using the Keyes' classification modified by Larson.

\begin{tabular}{|c|c|c|c|c|}
\hline \multirow{2}{*}{ Treatment } & \multicolumn{4}{|c|}{ Smooth-surface caries } \\
\hline & $E(M \pm S D)$ & Ds $(M \pm S D)$ & $\operatorname{Dm}(M \pm S D)$ & $D x(M \pm S D)$ \\
\hline Propolis varnish & $19.8(1.5)^{\mathrm{b}}$ & $13.4(5.2)^{\mathrm{b}, \mathrm{c}}$ & $1.4(1.4)^{\mathrm{a}}$ & $0.1(0.3)^{a}$ \\
\hline Gold standard* & $16.5(1.6)^{\mathrm{b}}$ & $10.3(4.6)^{c}$ & $0.1(0.4)^{b}$ & $0.0^{\circ}$ \\
\hline Chitosan Varnish** & $33.5(1.6)^{\mathrm{a}}$ & $19.8(5.9)^{\mathrm{a}}$ & $1.2(1.4)^{a, b}$ & $0.1(0.3)^{a}$ \\
\hline Untreated control ${ }^{* * *}$ & $28.3(1.5)^{\mathrm{a}}$ & $16.5(4.5)^{a, b}$ & $1.1(1.0)^{\mathrm{a}}$ & $0.3(0.6)^{a}$ \\
\hline
\end{tabular}

E: enamel caries; Ds: slight dentinal caries; Dm: moderate dentinal caries; Dx: extensive dentinal caries; ${ }^{*}$ Duraphat ${ }^{\circledR}$; ${ }^{* *}$ vehicle control, $^{2}$ *** untreated group. Different superscript letters in the same column indicate significant differences among treatments (One-way ANOVA with Tukey-Kramer HSD, $\mathrm{p} \leq$ 0.05).

Table 3. Effects of the treatment with the experimental propolis varnish on the development and severity of sulcal caries in rats. The values of the of the caries scores are given as mean \pm standard deviation using the Keyes' classification modified by Larson.

\begin{tabular}{|c|c|c|c|c|}
\hline \multirow{2}{*}{ Treatment } & \multicolumn{4}{|c|}{ Sulcal caries } \\
\hline & $E(M \pm S D)$ & $\mathrm{Ds}(\mathrm{M} \pm \mathrm{SD})$ & $\operatorname{Dm}(M \pm S D)$ & $\mathrm{Dx}(\mathrm{M} \pm \mathrm{SD})$ \\
\hline Propolis varnish & $43.2(6.5)^{a}$ & $34.6(6.7)^{a, b}$ & $14.6(4.6)^{\mathrm{b}}$ & $6.4(1.6)^{a}$ \\
\hline Gold standard* & $35.6(6.0)^{a}$ & $21.0(5.7)^{c}$ & $4.9(3.2)^{c}$ & $2.8(1.9)^{b}$ \\
\hline Chitosan Varnish** & $46.5(4.0)^{\mathrm{a}}$ & $40.0(5.9)^{a}$ & $20.1(4.2)^{a}$ & $7.5(2.5)^{a}$ \\
\hline Untreated control ${ }^{* * *}$ & $41.6(5.3)^{a}$ & $34.1(6.4)^{\mathrm{b}}$ & $15.4(4.2)^{a, b}$ & $6.0(2.4)^{a}$ \\
\hline
\end{tabular}

E: enamel caries; Ds: slight dentinal caries; Dm: moderate dentinal caries; Dx: extensive dentinal caries; ${ }^{*}$ Duraphat ${ }^{\boxplus} ;{ }^{* *}$ vehicle control, *** untreated group. Different superscript letters in the same column indicate significant differences among treatments (One-way ANOVA with Tukey-Kramer HSD, $p \leq 0.05$ ). 


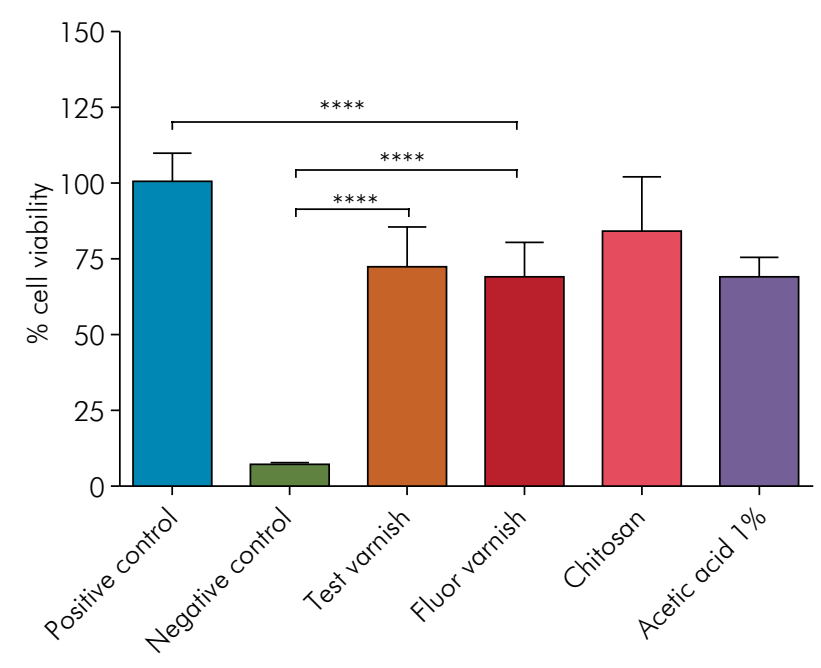

Figure 1. MTT-based viability assay of fibroblast culture after 24 hours in contact with the following materials: positive control (culture medium + cells); negative control (culture medium); test varnish (propolis varnish); fluoride-containing varnish (gold standard, Duraphat ${ }^{\circledR}$ ); vehicle control (chitosan varnish); and $1 \%$ acetic acid. Four asterisks $\left(^{* * * *}\right)$ indicate significant differences among the groups at $p<0.0001$ (One-way ANOVA with Tukey-Kramer HSD).

\section{Discussion}

Propolis contains bioactive molecules in its composition, which may affect several targets in the human body, including those related to the onset of oral diseases. Greater scientific knowledge of the chemical composition of various types of propolis has helped envision their potential use and application in dental practice. ${ }^{8,9,26,27}$

Previous studies have reported the strong antimicrobial activity of propolis against several bacteria of the oral microbiome, including S. mutans. ${ }^{1,2,28,29,30,31}$ As confirmed in our study, propolis and some of its isolated compounds, such as apigenin and $t t$-farnesol, ${ }^{11}$ have been found to display a major effect on microbial virulence (e.g., polysaccharide production and acid tolerance), rather than affecting unspecific or specific microbiome viability, considered a highly desirable quality.

In our study, the experimental propoliscontaining varnish was able to reduce the onset of smooth-surface caries in the enamel, similarly to the GS (Duraphat ${ }^{\circledR}$ ). However, it was not effective in diminishing the severity of carious lesions

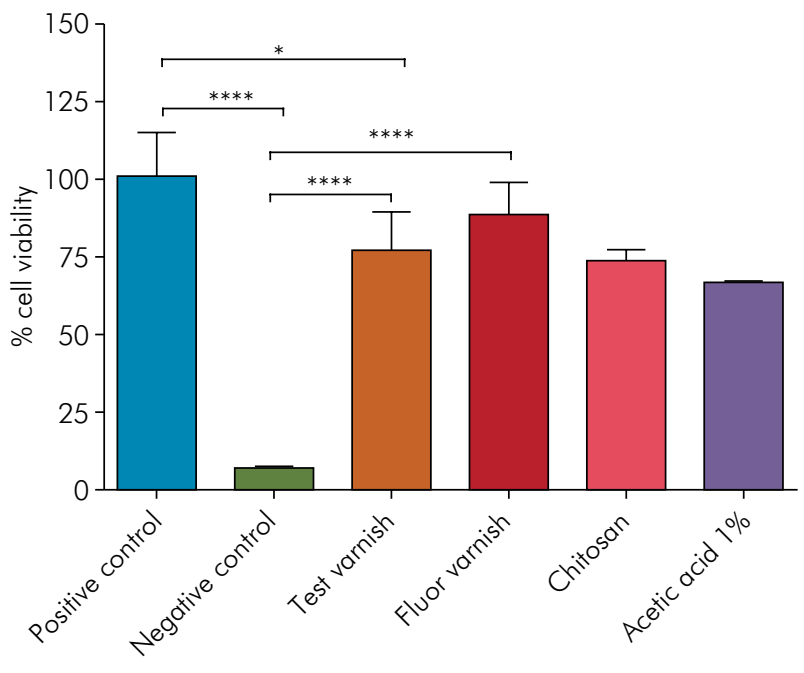

Figure 2. MTT-based viability assay of fibroblast culture after 48 hours in contact with the following materials: positive control (culture medium + cells); negative control (culture medium); test varnish (propolis varnish); fluoride-containing varnish (gold standard, Duraphat ${ }^{\circledR}$ ); vehicle control (chitosan varnish); and $1 \%$ acetic acid. Four asterisks $\left(^{* * * *}\right)$ indicate significant differences among the groups at $p<0.0001$ (One-way ANOVA with Tukey-Kramer HSD).

affecting dentin, either on smooth-surface or sulcal areas. While this result may mean that the propolis varnish had no satisfactory antimicrobial activity to prevent advanced smooth-surface and sulcal caries, one should take into consideration that such an effect was evaluated only at one endpoint, when the material was probably no longer adhered to the tooth structure. Hence, it seems pertinent to note that the experimental propolis varnish was found to be more effective against early smooth-surface lesions under a high cariogenic challenge. The lack of a residual effect confirms that propolis activity occurs while it is in direct contact with the teeth. Hence, repeated and prolonged applications of this new product could reduce the virulence of cariogenic bacteria, and thus achieve effective anti-caries activity. Further studies should also focus on the incorporation of isolated anti-caries compounds (e.g.: apigenin, $t t$-farnesol) into the varnish matrix.

Other studies have investigated the anti-caries effects of propolis extracts using this same animal model. 10,15,16,23,32 In these studies, ethanolic extracts of propolis, or its bioactive fractions, were applied 
topically to the molars of rats twice a day for a period of 4 to 5 weeks. Overall, the authors observed anti-caries activity similar to that of Duraphat ${ }^{\circledR}$. This result suggests that the continuing presence of propolis in the oral cavity enabled more effective antimicrobial activity, leading to a significant decrease in the severity of carious lesions.

The experimental propolis varnish was not cytotoxic against fibroblasts or osteoblasts, as previously reported, ${ }^{20}$ and showed no difference in comparison with the GS Duraphat ${ }^{\circledR}$. This suggests that application of propolis varnish in intimate contact with the oral tissues is not potentially harmful to host cells.

Chitosan is a biocompatible and biodegradable polymeric material ${ }^{33}$ with non-toxic and antimicrobial properties. ${ }^{34}$ Chitosan of medium molecular weight was used as a vehicle during preparation of the experimental varnish. Our results showed that the chitosan varnish (no active principle included) became inert as the severity of dental caries increased. This may be due to the molecular weight of chitosan used in the formulation, which is different from that generally used in other studies (using low molecular weight) to test the antimicrobial activity of dental products. ${ }^{710,14,33,35,36,37,38,39,40}$ Changes in the molecular weight of the chitosan used may have precluded polymeric film formation, which is necessary to mediate product adhesion to the teeth.

Fluoride, considered the GS in caries prevention, has little antimicrobial effects on the synthesis of glucans and acid tolerance in S. mutans, and its

\section{References}

1. Petersen PE, Bourgeois D, Ogawa H, Estupinan-Day S, Ndiaye $C$. The global burden of oral diseases and risks to oral health. Bull World Health Organ. 2005;83(9):661-9. https:/doi.org/10.1590/S0042-96862005000900011

2. Wolff D, Frese C, Maier-Kraus T, Krueger T, Wolff B. Bacterial biofilm composition in caries and caries-free subjects. Caries Res. 2013;47(1):69-77. https://doi.org/10.1159/000344022

3. Beighton D. The complex oral microflora of high-risk individuals and groups and its role in the caries process. Community Dent Oral Epidemiol. 2005;33(4):248-55. https://doi.org/10.1111/j.1600-0528.2005.00232.x mechanism of action is based on the physicochemical dynamics of ions in order to keep the integrity of the enamel hydroxyapatite mineral content. ${ }^{6}$ Fluoride prevents the onset of dental caries by reducing demineralization and enhancing remineralization of incipient lesions. ${ }^{15}$ Duraphat ${ }^{\circledR}$ is a fluoride-containing varnish, and was used as positive control in this experiment due to its proven effects in controlling dental caries. This varnish did not interfere with the total microbiota and SM counts - as expected, because of fluoride mechanism of action - but it significantly reduced the severity of carious lesions. Concerning smooth-surface enamel caries, there was no difference in the preventive effects of the experimental varnish versus the GS.

Further studies are now needed to establish an efficacious protocol to sustain long-term antimicrobial activity of the propolis varnish, particularly to prevent advanced dentinal carious lesions under a high cariogenic challenge.

\section{Acknowledgments}

The authors are grateful to the National Council for Scientific and Technological Development (CNPq) for the scholarship, and wish to thank André Augusto Gomes Faraco and Juçara Ribeiro Franca for manufacturing the propolis varnish, and Eliane Franco and José Carlos for their technical support, as well as Bruna Benso, Carina Denny, Laila Facin, Lívia Galvão, Camila Batista, Luiz Eduardo Ferreira, and Cleiton P. Santos for their valuable help in the experiments.

\footnotetext{
4. Choi EJ, Lee SH, Kim YJ. Quantitative real-time polymerase chain reaction for Streptococcus mutans and Streptococcus sobrinus in dental plaque samples and its association with early childhood caries. Int J Paediatr Dent. 2009;19(2):141-7. https://doi.org/10.1111/j.1365-263X.2008.00942.x

5. Head DA, Marsh PD, Devine DA. Non-lethal control of the cariogenic potential of an agent-based model for dental plaque. PLoS One. 2014;9(8):e105012. https://doi.org/10.1371/journal.pone.0105012
} 
6. Jeon JG, Rosalen PL, Falsetta ML, Koo H. Natural products in caries research: current (limited) knowledge, challenges and future perspective. Caries Res. 2011;45(3):243-63. https://doi.org/10.1159/000327250

7. Mishra BB, Tiwari VK. Natural products: an evolving role in future drug discovery. Eur J Med Chem. 2011 Oct;46(10):4769807. https://doi.org/10.1016/i.ejmech.2011.07.057

8. Libério SA, Pereira AL, Araújo MJ, Dutra RP, Nascimento FR, Monteiro-Neto $V$ et al. The potential use of propolis as a cariostatic agent and its actions on mutans group streptococci. J Ethnopharmacol. 2009;125(1):1-9. https://doi.org/10.1016/i.jep.2009.04.047

9. Freires IA, Alencar SM, Rosalen PL. A pharmacological perspective on the use of Brazilian Red Propolis and its isolated compounds against human diseases. Eur J Med Chem. 2016;110:267-79. https://doi.org/10.1016/i.ejmech.2016.01.033

10. Bueno-Silva B, Alencar SM, Koo H, Ikegaki M, Silva GV, Napimoga $\mathrm{MH}$ et al. Anti-Inflammatory and antimicrobial evaluation of neovestitol and vestitol isolated from Brazilian red propolis. J Agric Food Chem. 2013;61(19):4546-50. https://doi.org/10.1021/¡f305468f

11. Koo H, Hayacibara MF, Schobel BD, Cury JA, Rosalen PL, Park YK et al. Inhibition of Streptococcus mutans biofilm accumulation and polysaccharide production by apigenin and tt-farnesol. J Antimicrob Chemother. 2003;52(5):782-9. https://doi.org/10.1093/jac/dkg449

12. Castro ML, Nascimento AM, Ikegaki M, Costa-Neto CM, Alencar SM, Rosalen PL. Identification of a bioactive compound isolated from Brazilian propolis type 6. Bioorg Med Chem. 2009;17(14):5332-5. https://doi.org/10.1016/i.bmc.2009.04.066

13. Park YK, Alencar SM, Scamparine ARP, Aguiar CL. [Propolis produced in South Brazil, Argentine and Uruguay: phytochemical evidence for the plant origin]. Cienc Rural. 2002 2;32(6):997-1003. Portuguese. https://doi.org/10.1590/S0103-84782002000600013

14. Ikeno K, Ikeno T, Miyazawa C. Effects of propolis on dental caries in rats. Caries Res. 1991;25(5):347-51. https://doi.org/10.1159/000261390

15. Duarte S, Rosalen PL, Hayacibara MF, Cury JA, Bowen WH, Marquis RE et al. The influence of a novel propolis on mutans streptococci biofilms and caries development in rats. Arch Oral Biol. 2006;51(1):15-22. https://doi.org/10.1016/i.archoralbio.2005.06.002

16. Koo H, Rosalen PL, Cury JA, Park YK, Ikegaki M, Sattler A. Effect of Apis mellifera propolis from two Brazilian regions on caries development in desalivated rats. Caries Res. 1999;33(5):393-400. https://doi.org/10.1159/000016539

17. Petersson LG, Twetman S, Dahlgren H, Norlund A, Holm AK, Nordenram $G$ et al.. Professional fluoride varnish treatment for caries control: a systematic review of clinical trials. Acta Odontol Scand. 2004;62(3):170-6. https://doi.org/10.1080/00016350410006392
18. Marinho VC, Worthington HV, Walsh T, Clarkson JE. Fluoride varnishes for preventing dental caries in children and adolescents. Cochrane Database Syst Rev. 2013;(7):CD002279. https://doi.org/10.1002/14651858.CD002279.pub2

19. Jayabal J, Mahesh R. Current state of topical antimicrobial therapy in management of early childhood caries. ISRN Dent. 2014;2014:ID762458. https://doi.org/10.1155/2014/762458

20. De Luca MP, Franca JR, Macedo FA, Grenho L, Cortes ME, Faraco AA, Moreira AN, Santos VR. Propolis varnish: antimicrobial properties against cariogenic bacteria, cytotoxicity, and sustained-release profile. Biomed Res Int. 2014;2014:ID348647. https://doi.org/10.1155/2014/348647

21. Keyes PH. Dental caries in the Syrian bamster. VIII. The induction of rampant caries activity in albino and golden animals. J Dent Res. 1959;38(3):525-33. https://doi.org/10.1177/00220345590380031401

22. Murata RM, Branco-de-Almeida LS, Franco EM, Yatsuda R, Santos MH, Alencar SM et al. Inhibition of Streptococcus mutans biofilm accumulation and development of dental caries in vivo by 7-epiclusianone and fluoride. Biofouling. 2010;26(7):865-72. https://doi.org/10.1080/08927014.2010.527435

23. Hayacibara MF, Koo H, Rosalen PL, Duarte S, Franco EM, Bowen WH et al. In vitro and in vivo effects of isolated fractions of Brazilian propolis on caries development. J Ethnopharmacol. 2005;101(1-3):110-5. https://doi.org/10.1016/i.jep.2005.04.001

24. Larson RM. Merits and modifications of scoring rat dental caries by Keyes' method. In: Tanzer JM, editor. Animal models in cariology. Proceedings of a Symposium and Workshop on Animal Models in Cariology, April 21-23, 1980, Sturbridge. Washington, DC: IRL; 1981. p. 195-203.

25. Gala-García A, Carneiro MB, Silva GA, Ferreira LS, Vieira $L Q$, Marques $M M$ et al. In vitro and in vivo evaluation of the biocompatibility of a calcium phosphate/poly(lactic-co-glycolic acid) composite. J Mater Sci Mater Med. 2012;23(7):1785-96. https://doi.org/10.1007/s10856-012-4657-8

26. Vagish Kumar LS. Propolis in dentistry and oral cancer management. N Am J Med Sci. 2014;6(6):250-9. https://doi.org/10.4103/1947-2714.134369

27. Więckiewicz W, Miernik M, Więckiewicz M, Morawiec T. Does propolis help to maintain oral health? Evid Based Complement Alternat Med. 2013;2013:ID351062. https://doi.org/10.1155/2013/351062

28. Anauate Netto C, Marcucci MC, Paulino N, Anido-Anido A, Amore R, Mendonça $S$ et al. Effects of typified propolis on mutans streptococci and lactobacilli: a randomized clinical trial. Braz Dent Sci. 2013;16(2):31-6. https://doi.org/10.14295/bds.2013.v16i2.879

29. Barrientos L, Herrera CL, Montenegro G, Ortega X, Veloz J, Alvear $M$ et al. Chemical and botanical characterization of Chilean propolis and biological activity on cariogenic bacteria Streptococcus mutans and Streptococcus sobrinus. Braz J Microbiol. 2013;44(2):577-85. https://doi.org/10.1590/S1517-83822013000200038 
The anti-caries activity and toxicity of an experimental propolis-containing varnish

30. Tulsani SG, Chikkanarasaiah N, Siddaiah SB, Krishnamurthy NH. The effect of Propolis and Xylitol chewing gums on salivary Streptococcus mutans count: A clinical trial. Indian J Dent Res. 2014;25(6):737-41. https://doi.org/10.4103/0970-9290.152182

31. Mohsin S, Manohar B, Rajesh S, Asif Y.

The effects of a dentifrice containing propolis on Mutans Streptococci: a clinico-microbiological study. Ethiop J Health Sci. 2015;25(1):9-16. https://doi.org/10.4314/ejhs.v25i1.3

32. Koo H, Pearson SK, Scott-Anne K, Abranches J, Cury JA, Rosalen PL et al. Effects of apigenin and tt-farnesol on glucosyltransferase activity, biofilm viability and caries development in rats. Oral Microbiol Immunol. 2002;17(6):337-43. https://doi.org/10.1034/j.1399-302X.2002.170602.x

33. Uysal T, Akkurt MD, Amasyali M, Ozcan S, Yagci A, Basak $F$ et al. Does a chitosan-containing dentifrice prevent demineralization around orthodontic brackets? Angle Orthod. 2011;81(2):319-25. https://doi.org/10.2319/062910-359.1

34. Busscher HJ, Engels E, Dijkstra RJ, van der Mei HC. Influence of a chitosan on oral bacterial adhesion and growth in vitro. Eur J Oral Sci. 2008;116(5):493-5. https://doi.org/10.1111/j.1600-0722.2008.00568.x
35. No HK, Park NY, Lee SH, Meyers SP. Antibacterial activity of chitosans and chitosan oligomers with different molecular weights. Int J Food Microbiol. 2002;74(1-2):65-72. https://doi.org/10.1016/S0168-1605(01)00717-6

36. Decker EM, von Ohle C, Weiger R, Wiech I, Brecx M. A synergistic chlorhexidine/chitosan combination for improved antiplaque strategies. J Periodontal Res. 2005;40(5):373-7. https://doi.org/10.1111/j.1600-0765.2005.00817.x

37. Salamat-Miller N, Chittchang M, Johnston TP. The use of mucoadhesive polymers in buccal drug delivery. Adv Drug Deliv Rev. 2005;57(11):1666-91. https://doi.org/10.1016/i.addr.2005.07.003

38. Chen CY, Chung YC. Antibacterial effect of water-soluble chitosan on representative dental pathogens Streptococcus mutans and Lactobacilli brevis. J Appl Oral Sci. 2012;20(6):620-7. https://doi.org/10.1590/S1678-77572012000600006

39. Costa EM, Silva S, Tavaria FK, Pintado MM. Study of the effects of chitosan upon Streptococcus mutans adherence and biofilm formation. Anaerobe. 2013;20:27-31. https://doi.org/10.1016/i.anaerobe.2013.02.002

40. Costa EM, Silva S, Madureira AR, Cardelle-Cobas A, Tavaria FK, Pintado MM. A comprehensive study into the impact of a chitosan mouthwash upon oral microorganism's biofilm formation in vitro. Carbohydr Polym. 2014;101:1081-6. https://doi.org/10.1016/i.carbpol.2013.09.041 